\title{
Multiscale analysis of SRY-positive 46,XX testicular disorder of sex development: Presentation of nine cases
}

\author{
Omer Salih Akar $^{1}$ (D) | Sezgin Gunes ${ }^{2}$ (D) | Ummet Abur ${ }^{1}$ (D) | Engin Altundag ${ }^{1}$ (D) | \\ Ramazan Asci $^{3}$ (D) | Onur Emre Onat ${ }^{4}$ (D) | Tayfun Ozcelik ${ }^{4}$ (D) | Gonul Ogur ${ }^{1}$ (D)
}

${ }^{1}$ Department of Medical Genetics, Faculty of Medicine, Ondokuz Mayis University, Samsun, Turkey

${ }^{2}$ Department of Medical Biology, Faculty of Medicine, Ondokuz Mayis University, Samsun, Turkey

${ }^{3}$ Department of Urology, Faculty of Medicine, Ondokuz Mayis University, Samsun, Turkey

${ }^{4}$ Department of Molecular Biology and Genetics, Bilkent University, Ankara, Turkey

\section{Correspondence}

Sezgin Gunes, Department of Medical Biology, Faculty of Medicine, Ondokuz Mayis University, 55139 Samsun, Turkey. Email: sgunes@omu.edu.tr

\begin{abstract}
$46, X X$ testicular disorder of sex development (46,XX TDSD) is a relatively rare condition characterised by the presence of testicular tissue with 46,XX karyotype. The present study aims to reveal the phenotype to genotype correlation in a series of sexdetermining region $Y$ (SRY)-positive 46,XX TDSD cases. We present the clinical findings, hormone profiles and genetic test results of six patients with SRY-positive 46,XX TDSD and give the details and follow-up findings of our three of previously published patients. All patients presented common characteristics such as azoospermia, hypergonadotropic hypogonadism and an SRY gene translocated on the terminal part of the short arm of one of the $X$ chromosomes. Mean \pm standard deviation (SD) height of the patients was $164.78 \pm 8.0 \mathrm{~cm}$. Five patients had decreased secondary sexual characteristics, and three patients had gynaecomastia with varying degrees. Five of the seven patients revealed a translocation between protein kinase $X(P R K X)$ and inverted protein kinase $Y(P R K Y)$ genes, and the remaining two patients showed a translocation between the pseudoautosomal region 1 (PAR1) of $X$ chromosome and the differential region of $Y$ chromosome. $X$ chromosome inactivation $(\mathrm{XCl})$ analysis results demonstrated random and skewed $\mathrm{XCl}$ in 5 cases and 1 case, respectively. In brief, we delineate the phenotypic spectrum of patients with SRY-positive 46,XX TDSD and the underlying mechanisms of Xp;Yp translocations.
\end{abstract}

\section{KEYWORDS}

array-CGH, infertility, SRY-positive $46, \mathrm{XX}$ male, $\mathrm{X}$ chromosome inactivation

\section{1 | INTRODUCTION}

46,XX testicular disorder of sex development (46,XX TDSD) (MIM 400045) was first described by De la Chapelle, Hortling, Niemi, and Wennström (1964) and generally characterised by a male phenotype despite having a female karyotype. The incidence is estimated to be one in 20,000 male newborns. Patients with sex-determining region $Y$ (SRY)-positive 46,XX TDSD are usually asymptomatic males diagnosed in puberty or adulthood because of hypergonadotropic hypogonadism, microorchidism, and infertility due to azoospermia and Sertoli cells only (Delot \& Vilain, 1993; Ropke \& Tuttelmann, 2017; Zenteno-Ruiz, Kofman-Alfaro, \& Mendez, 2001). Until the early stages of puberty,
Sertoli and Leydig cells are functional in these patients. Sertoli cells produce anti-mullerian hormone (AMH), which is responsible for the regression of müllerian ducts, and Leydig cells synthesise testosterone and dihydrotestosterone to drive the differentiation of derivatives of the Wolffian duct in developing male fetuses. Therefore, these patients have normal internal and external male genitalia with an average gonadal size during childhood. Germ cell proliferation and growth in seminiferous tubules are triggered by the onset of puberty. During the adolescence and adulthood with the effect of the extra $X$ chromosome, testicles remain smaller than normal and cause to spermatogenic failure because of the dramatic germ cell loss during meiosis. Absence of azoospermia factor (AZF)a, AZFb and AZFc regions results 
in Sertoli cell-only syndrome (SCOS; Kamp et al., 2001), maturation arrest and azoospermia, respectively (Krausz \& Riera-Escamilla, 2018). The probability of sperm retrieval is virtually zero in patients with complete AZFa and AZFb microdeletions; therefore, assisted reproductive techniques are not recommended to these patients (Grinspon \& Rey, 2019). Although all patients generally have small testicular tissues, the external genitalia varies from normal virilised male to ambiguous genitalia depending on the presence and length of SRY gene. Hence, SRYnegative patients tend to be more frequently having genital ambiguities compared to SRY-positive ones. Approximately $80 \%-90 \%$ of $46, \mathrm{XX}$ TDSD patients have SRY gene which is usually translocated on the distal portion of the short arm of an X chromosome (Chen et al., 2019; Dauwerse, Hansson, Brouwers, Peters, \& Breuning, 2006; Gunes \& Esteves, 2020; Queralt et al., 2008; Ropke \& Tuttelmann, 2017; Zenteno-Ruiz et al., 2001). Typical features of SRY-positive 46,XX TDSD patients are female karyotype with completely normal male phenotype and virilised male external genitalia, small testes, azoospermia and hypergonadotropic hypogonadism (Akinsal, Baydilli, Demirtas, Saatci, \& Ekmekcioglu, 2017; Ropke \& Tuttelmann, 2017). Patients usually come to attention after puberty because of hypogonadism and infertility (Zenteno-Ruiz et al., 2001). Gynaecomastia, sparse body and/or pubic hair, cryptorchidism and/or hypospadias could also be detected in these patients (Majzoub et al., 2017).

SRY-positive 46,XX TDSD results from an aberrant $Y$ to $X$ translocation during the paternal meiosis. Either the nonallelic homologous recombination (NAHR) between the identical sequences $X$ - and $Y$ chromosome or spontaneous errors during the replication-based mechanisms could mediate the $\mathrm{Xp} ; \mathrm{Yp}$ translocations in $90 \%$ of cases (Giglio et al., 2002).

Clinical pictures of the patients with $46, X X$ TDSD are heterogeneous ranging from infertile men seeking fertility with normal male internal and external genitalia to the child attending to urology and child health clinics at an early age due to the ambiguous genitalia or micropenis (Majzoub et al., 2017). Therefore, the present study aimed to reveal the clinical and genetic findings of this heterogeneous group of patients in the view of our nine patients with SRY-positive 46,XX-DSD. Additionally, we aimed to evaluate the molecular basis of this disorder based on the results of array comparative genomic hybridisation (array-CGH) analysis.

\section{2 | MATERIALS AND METHODS}

\section{1 | Clinical evaluation of patients}

Nine patients with SRY-positive 46,XX TDSD out of 1,300 consecutive infertile men (548 severe oligozoospermic and 752 azoospermic patients) attending to Urology Clinics of the Ondokuz Mayis University between 2004 and 2017 were enrolled in the present study. The study was approved by the Ondokuz Mayıs University Clinical Research Ethical Committee (Approval No: 2018/353), and patients signed informed consent before participating in the study. The medical and family history, detailed physical examination including measuring of height, weight and body mass indexes, an inspection of the external genitalia and assessment of secondary sex characteristics were evaluated. Testicular volumes of these patients were calculated using the formula [length $(L) \times$ width $(W) \times$ height $(\mathrm{H}) \times 0.52$ with the dimensions] obtained by testicular ultrasound.

Serum levels of follicle-stimulating hormone (FSH), luteinising hormone (LH), prolactin (PRL), oestradiol (E2) and total testosterone (TT) were measured using a radioimmunoassay in all patients. Semen samples were processed within $1 \mathrm{hr}$ after the collection and liquefaction and then analysed according to the World Health Organization (WHO) guidelines in the year of investigation (1999 or 2010) by the same laboratory technician.

The clinical data, karyotype and fluorescence in situ hybridisation (FISH) findings, and $\mathrm{X}$ chromosome inactivation (XCI) patterns of three of our patients had been reported previously (Gunes et al., 2013). However, array-CGH data have not been analysed and published in our previous publication. Therefore, array-CGH and follow-up findings of these cases after publication have also been included in the present study.

\section{2 | Cytogenetic analysis}

Peripheral blood samples were obtained from all patients for chromosomal analysis. Blood lymphocytes were cultured using modified methotrexate-thymidine synchronisation method and GTG banding as previously described (Abur et al., 2019; Rooney, 2001). Chromosomal analyses were assessed with CytoVision software (version 3.93; Applied Imaging).

\section{3 | Fluorescence in situ hybridisation analysis}

FISH analyses were conducted on both metaphase spreads and interphase nuclei with (SRY/CEPX; Vysis; Gunes et al., 2013). Image analyses were evaluated using CytoVision software (version 3.93; Applied Imaging) with Olympus BX51 microscope equipped with Progressive Scan Video Camera.

\section{4 | DNA extraction}

The genomic DNA was extracted from peripheral blood lymphocytes using QIAamp DNA Blood Mini Kit (Qiagen $\mathrm{GmbH}$ ) according to the manufacturer's instruction (Abur et al., 2019).

\section{5 | Array comparative genomic hybridisation analysis}

Array-CGH analysis was carried out in $7 / 9$ patients using a $60 \mathrm{~K}$ oligonucleotide microarray (Agilent Technologies) as described 
जิ
+1
$\stackrel{+}{\Xi}$
$\stackrel{\Xi}{\Sigma}$

ป

$\begin{array}{lllll}+1 & +1 & +1 & +1 & +1\end{array}$

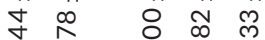

की के 过

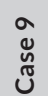

:

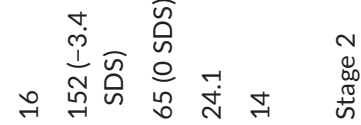

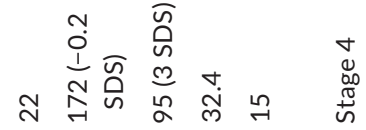

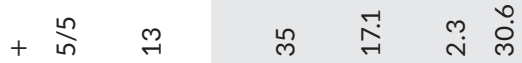

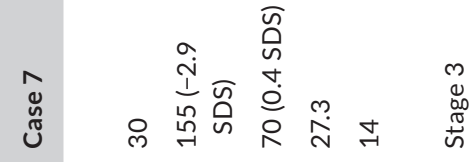

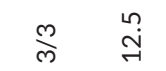

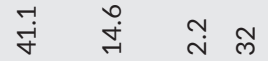

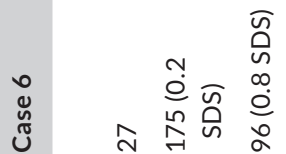

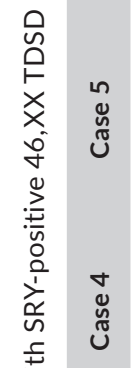

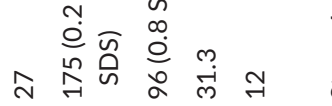

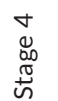

$+\frac{\infty}{b} \stackrel{m}{\rightarrow}$

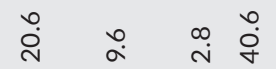

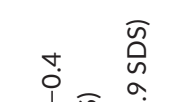

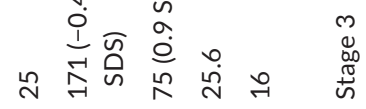

$+\frac{4}{4} \quad A$

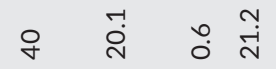

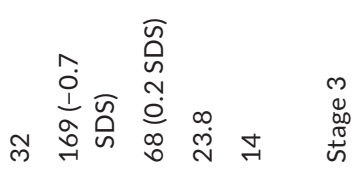

$\stackrel{m}{m} \quad \forall$

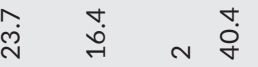

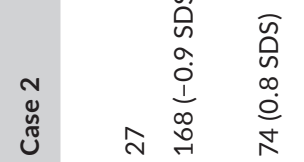

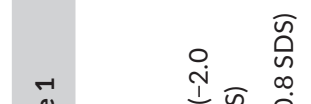

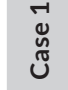

ल<smiles>[Al]C=[Ge]</smiles>

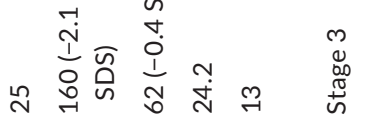

$\stackrel{m}{m}$ 근

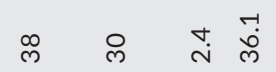<smiles>[C-]1=CCCCC1</smiles>

ล

$\stackrel{\infty}{\forall} \underset{\ddots}{*}$

$\stackrel{m}{\infty}$ ने

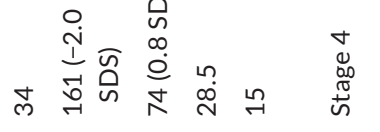

$+\infty \frac{\infty}{\infty}$ 욱

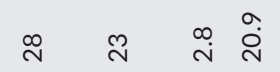




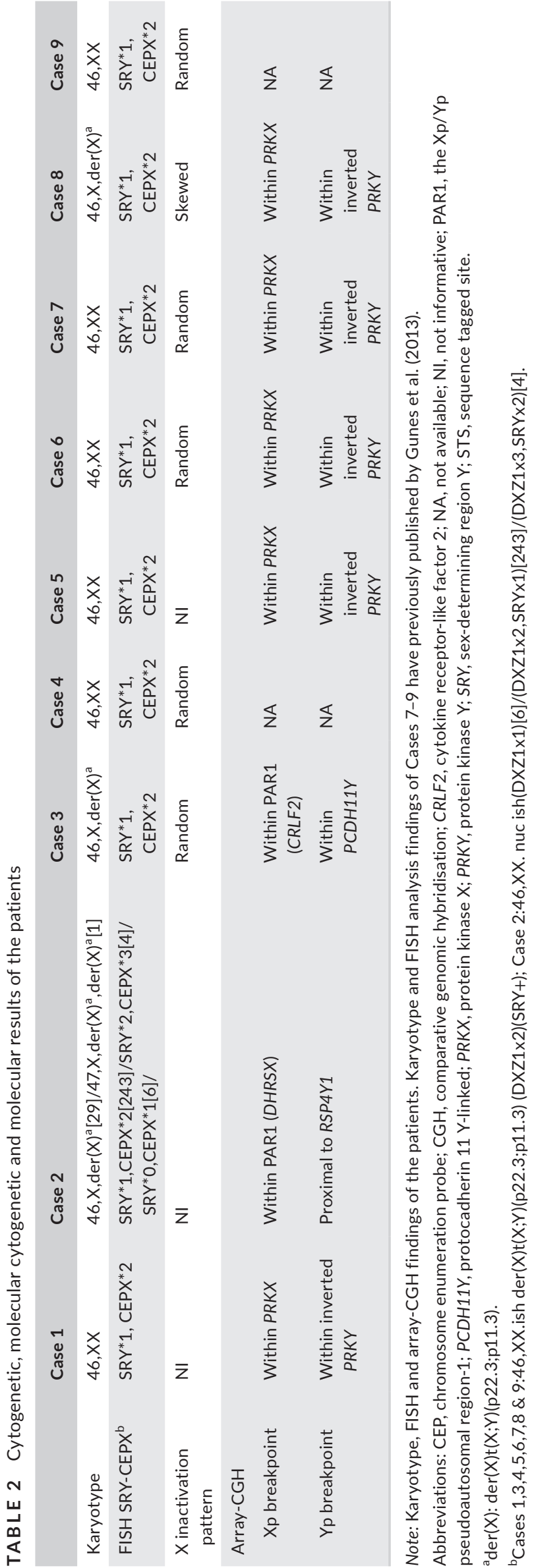

elsewhere (Pinkel et al., 1998). DNA samples of Case 4 and Case 9 were inadequate; therefore, we could not perform array-CGH analysis to two of these patients. Human male genomic DNA was used as reference DNA for the array-CGH analysis. Labelling with $\mathrm{Cy} 3$ and Cy5, washing and scanning steps were performed following a standard protocol. Data extraction was carried out using Agilent Feature Extraction Software, and the data analysis was assessed on Agilent Cytogenomics Software (v.2.0.6.0; Agilent Technologies). Data included imbalances with at least three consecutive probes with abnormal log2 ratios. The probe sequences and gene annotations were based on GRCh37/hg19 assembly

Karyotype results, FISH and array-CGH analyses were described according to the International System for Human Cytogenetic Nomenclature 2016.

\subsection{X chromosome inactivation analysis}

The polymorphic region of exon 1 of the androgen receptor $(A R)$ gene was used to assess the $\mathrm{XCl}$ patterns of the patients. The genomic DNA was cleaved using methylation-sensitive restriction enzyme Hpall (MBI Fermentas) which digests the active $X$ chromosome (unmethylated) fragments. After amplification of $A R$ gene exon 1 using PCR, amplicons were separated on $8 \%$ denaturing acrylamide: bisacrylamide (29:1) gel for $4 \mathrm{hr}$. Then, the densitometric analysis of the alleles was carried out with MultiAnalyst version 1.1 software (Bio-Rad; Gunes et al., 2013).

\section{7 | Data analysis}

Data were analysed using SPSS Statistics Version 22.0. Results were expressed as mean and standard deviation (SD) for continuous variables. Standard deviation scores (SDS) of height and weight were calculated using the following formula:

$\mathrm{SDS}=$ (observed value - median value of the reference population) $/$ standard deviation value of reference population

\section{3 | RESULTS}

\section{1 | Clinical findings}

Nine male patients were diagnosed with SRY-positive 46,XX TDSD. All cases demonstrated male phenotype with similar clinical findings, including small testes, hypergonadotropic hypogonadism and pellet-negative azoospermia. Clinical and laboratory findings of our six new patients and three of our previously published patients were presented in Table 1. Mean $\pm S D$ height of the patients was calculated to be $164.78 \pm 8.0 \mathrm{~cm}$, and these mean adult heights are apparently shorter than the normal adult Turkish men $(164.78 \pm 8.0$ vs. $174.3 \pm 4.9 \mathrm{~cm}$ ) (Aslan et al., 2011; Soylemez et al., 2012). Five out of $9(55 \%)$ patients had decreased secondary sex characteristics. 


\section{X chromosome}

\section{$Y$ chromosome}

Case 1, 5, 6, 7 \& 8

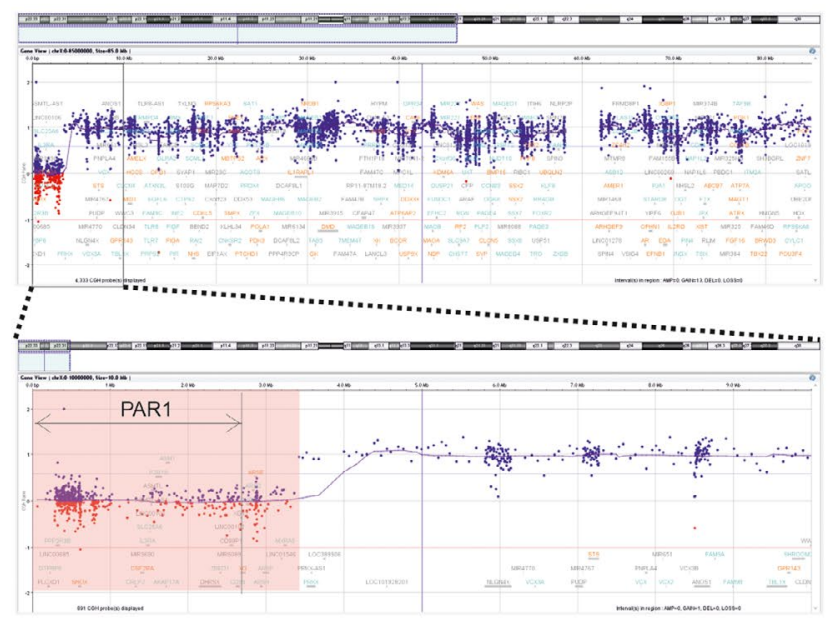

\section{Case 2}

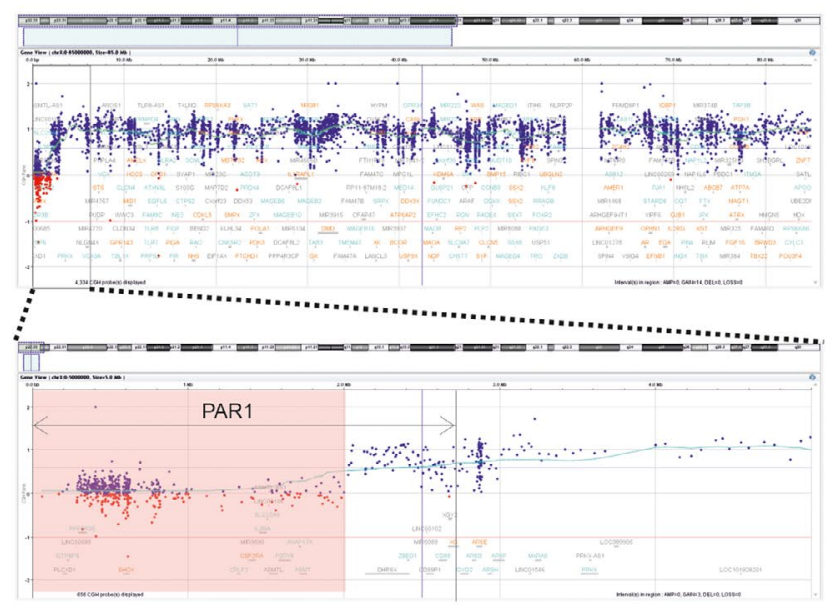

\section{Case 3}

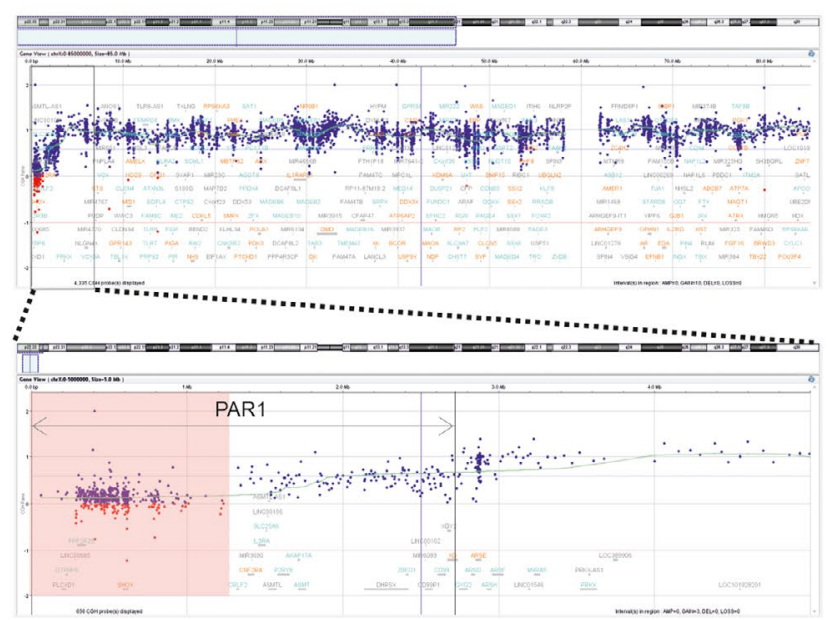

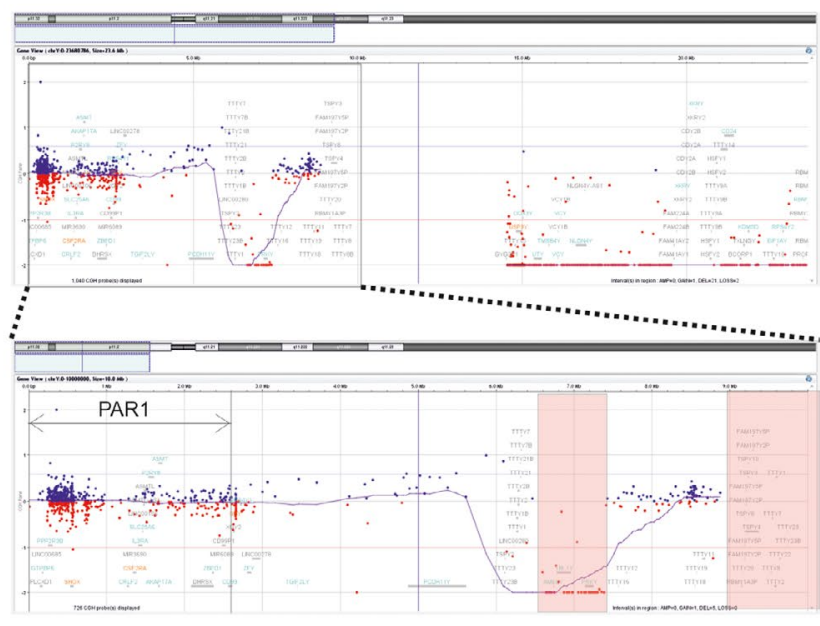
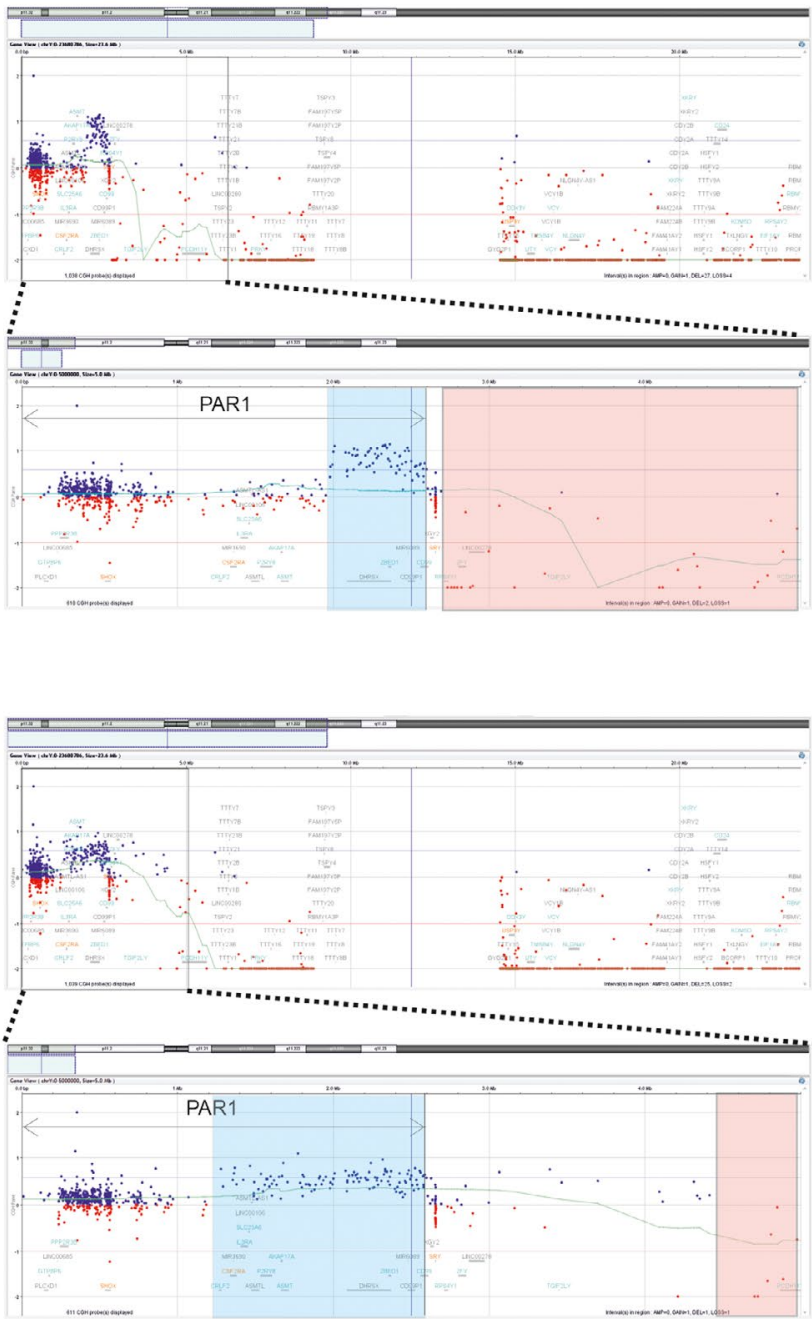

FIGURE 1 Representative results of the array CGH analysis. The segments highlighted with red and blue rectangles represent the decreased and increased copy numbers, respectively. PAR1 regions of $X$ and $Y$ chromosomes are indicated with the lines. 
Stretched penile length mean $\pm S D$ of our patients was found to be $12.39 \pm 1.3 \mathrm{~cm}$.

Additionally, clinical follow-up of our three previously published cases (Case 7-9) was included in the present study. Case 9 has been diagnosed 12 years ago. After his diagnosis with 46,XX TDSD, he started to receive intermittent testosterone replacement treatment. His height increased $12 \mathrm{~cm}$ after starting of testosterone replacement therapy. He is still single, and his gynaecomastia increased depending on the testosterone treatment. His erectile function is normal with testosterone treatment. Case 8 is still single as well and his erectile function, libido and ejaculation are normal under testosterone therapy. He received antidepressant therapy for a time to overcome the depression symptoms. Case 7 is still married, and his sexual functions are normal.

\section{2 | Karyotype and FISH analysis}

Six out of nine patients revealed $46, X X$ karyotype and the remaining three showed 46,X,der(X)t(X;Y)(p22.3;p11.3) karyotype. The karyotype of one out of these three patients with derivative $X$ chromosome demonstrated low level somatic chromosomal mosaicism $[46, X, \operatorname{der}(X)(29) / 47, X, \operatorname{der}(X), \operatorname{der}(X)(1)]$. FISH analysis of this patient showed that $S R Y$ gene region was translocated on the distal terminal of the short arm of one of the $X$ chromosomes and mosaicism of $45, X / 46, X, \operatorname{der}(X) / 47, X, \operatorname{der}(X), \operatorname{der}(X)$ cell lines. Low level of $45, X$-bearing cell lines detected by cytogenetic analysis in this patient, but could not be in FISH analysis (Table 2).

\section{3 | Array-CGH analysis}

Array-CGH analysis findings of seven out of nine patients were presented in Figure 1, and these results are summarised in Table 2. Five out of seven patients had two copies of the pseudoautosomal region 1 (PAR1), an approximately $1.0 \mathrm{Mb}$ deletion in X-differential region with breakpoints on protein kinase $X(P R K X)$, gene and $\sim 7 \mathrm{Mb}$ deletion in Yp-differential region, including an $\sim 0.6-\mathrm{Mb}$ interstitial deletion with the breakpoint on protein kinase $Y(P R K Y)$. These findings were compatible with an $Y p$ to $X p$ translocation resulting from a common $\sim 3.5 \mathrm{Mb}$ paracentric $\mathrm{Yp}$ inversion. The remaining two patients had three copies of the proximal and two copies of the distal part of the PAR1, indicating Xp terminal deletion in the PAR1 region and presence of the $Y p$ terminal segments including PAR1 region and a very distal portion of $Y$-differential region. These results were in concordance with the $\mathrm{Xp} ; Y \mathrm{p}$ translocation associated with the breakpoints inside of the X-PAR1 and inside of the $Y$-differential region (Figure 2). Additionally, array-CGH analysis also revealed the absence of AZFa, AZFb and AZFc in the patients.

\section{$3.4 \mathrm{XCl}$ analysis}

The methylation analysis of the $A R$ gene yielded random and skewed $\mathrm{XCl}$ in five patients in one patient respectively (Figure 3). A single polymorphic allele was observed in exon 1 of $A R$ gene for Case 1 , Case 2 and Case 5; therefore, the $\mathrm{XCl}$ analyses of these patients were accepted noninformative. These findings could be explained by the presence of two alleles with the same repeat number or alleles do not amplify under the same conditions (Table 2).

\section{DISCUSSION}

In the present study, seven of our patients applied to our clinic with infertility complaints, one with intermittent scrotal pain in adulthood and one with hypogonadism in puberty. All our patients had hypogonadism and azoospermia with $46, \mathrm{XX}$ or $46, \mathrm{X}, \operatorname{der}(\mathrm{X})$ karyotypes with translocated SRY locus onto $\mathrm{Xp}$. None of them had genital ambiguity consistent with literature data.

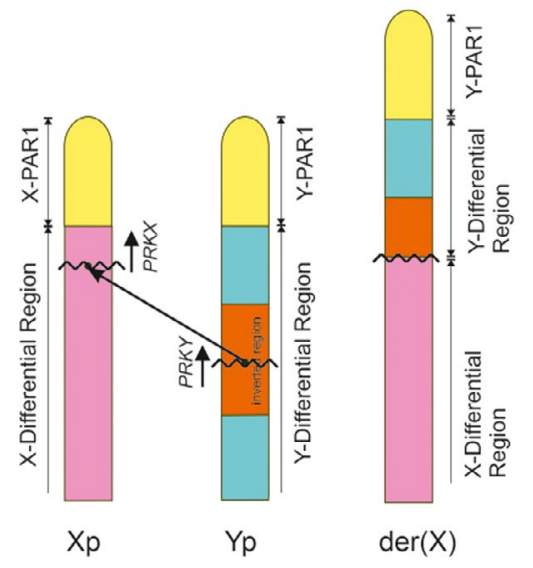

Case 1, Case 5, Case 6, Case 7 \& Case 8
Case 2 \& Case 3

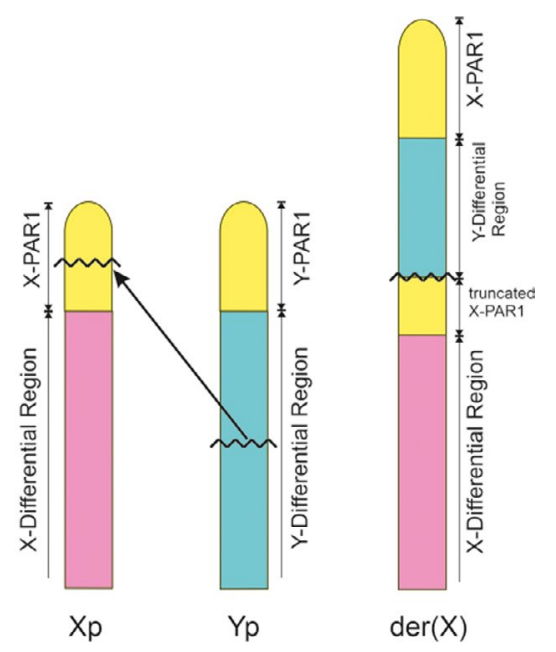

FIGURE 2 Schematic representation of the aberrations. The yellow, the pink, the blue and the green segments denote the PAR1, the $X$-differential region, the $\mathrm{Y}$-differential region and the $\mathrm{Y}$-differential inverted region, respectively. 


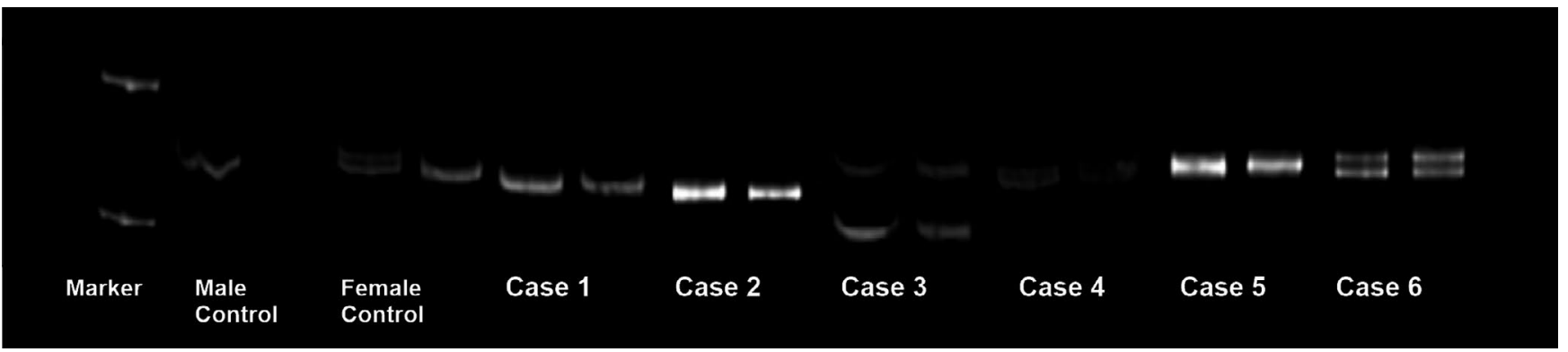

FIGURE 3 XCI patterns of Cases 1-6, PCR products of undigested and Hpall-digested DNA from peripheral blood. Line 1: marker 242and 331-bp fragments are visible; line 2 and 3: normal male control; line 4 and 5: normal female control; line 5 and 6: case 1; line 6-17 shows the results of the cases as the first line is 'undigested' and the second line as 'Hpall-digested' DNA for each patient.

Testosterone synthesis was found to be impaired and decreased with an increase in FSH and $\mathrm{LH}$ levels after puberty (Anik, Catli, Abaci, \& Bober, 2013; Vorona, Zitzmann, Gromoll, Schuring, \& Nieschlag, 2007). It was proposed that testosterone levels may be normal during adolescence but decreased in adulthood (Velasco, Savarese, Sandorfi, Jimenez, \& Jabbour, 2011). Additionally, the testosterone-to-oestradiol ratio was observed to be related to gynaecomastia, and poor axillary and pubic hair after puberty. Variations were observed in the secondary sexual characteristics among the patients. These variations have been suggested to be associated with the length of the translocated SRY gene region (Nakashima et al., 2014; Sharp et al., 2005). However, we have not found any significant correlation between the length of translocated SRY region and secondary sexual characteristics. Testosterone replacement therapy has been reported to cause the gynaecomastia as a result of the aromatisation of exogenous androgen (Rhoden \& Morgentaler, 2004). Therefore, the increase in gynaecomastia with testosterone replacement treatment in Case 9 may be explained with the aromatisation of exogenous androgen. We did not observe under-masculinised external genitalia among the patients, but the stretched penile length mean of our patients was found to be slightly shorter than normal healthy Turkish men (12.39 \pm 1.3 vs. $13.7 \pm 1.6$ and $13.98 \pm 1.6)$ (Aslan et al., 2011; Soylemez et al., 2012).

One of the characteristic clinical findings of the patients was short stature which is compatible with the literature. The mean height of our patients was apparently shorter than the mean height of normal adult Turkish men (164.78 $\pm 8.0 \mathrm{~cm}$ vs. $173.2 \mathrm{~cm}, 174.79 \pm 5.44$ $174.3 \pm 4.9$ ) (Aslan et al., 2011; Ozer, 2008; Soylemez et al., 2012), and the height of the patients has closely been resembled the mean height Turkish women $(164.78 \pm 8.0 \mathrm{~cm}$ vs. $158.9 \pm 6.4 \mathrm{~cm}$ and $161.4 \mathrm{~cm}$ ) (Ozer, 2008). The impaired testosterone-driven pubertal growth is proposed to be the primary cause of short stature in these patients. Case 9 had been diagnosed at puberty, although his height increased $12 \mathrm{~cm}$ with the testosterone replacement therapy, he still is shorter than normal adult Turkish men $(162.0 \mathrm{~cm}$ vs. $173.2 \mathrm{~cm}$, $174.79 \pm 5.44,174.3 \pm 4.9$ ) (Aslan et al., 2011; Ozer, 2008; Soylemez et al., 2012). Despite the fact that the patients with Klinefelter syndrome also show both hypogonadism and testosterone deficiency, they present tall stature compared to those of SRY-positive $46, \mathrm{XX}$
TDSD patients (Kirsch, Weiss, Zumbach, \& Rappold, 2004). This discrepancy could partly be explained by the absence of $Y$ chromosome material except $S R Y$ gene in these patients. Therefore, the $Y$ chromosome could be suggested to play a role in the control of growth and development of men and have an impact on the male stature. Furthermore, it has also been hypothesised that the expression of short stature homeobox (SHOX) gene has an impact on the growth of these patients (Rappold et al., 2002).

SRY-positive 46,XX TDSD results from translocation of Yp to $\mathrm{Xp}$ with various mechanisms and several breakpoint locations. The array- $\mathrm{CGH}$ analysis showed two main mechanisms leading to $X p ; Y p$ translocations in our patients. The first mechanism is NAHR, which occurs between the homologous sequences of short arms of $X$ - and $Y$ chromosomes, and the second one is replication-based mechanisms takes place between the nonhomologous sequences. NAHR causes to $\mathrm{Xp} ; \mathrm{Yp}$ translocation in Cases 1, 5, 6, 7 and 8. The most common paracentric inversion of the $\mathrm{Yp}$, about 3.5-Mb length, results in the displacement of $P R K Y$ and $P R K X$ genes in the same direction. These genes are located outside of the PAR1 of both in $\mathrm{X}$ - and $\mathrm{Y}$ chromosomes and show a high sequence similarity, but they are orientated in two opposite directions. Therefore, the homology of these sequences may lead to the crossover errors between the $X$ - and $Y$ chromosomes and creates an ectopic recombination during paternal meiosis (Jobling et al., 1998; Nakashima et al., 2014; Wang et al., 1995). Replication-based mechanism seems to be responsible for the translocations between the nonhomologous parts of $\mathrm{Xp}$ and $\mathrm{Yp}$ in Case 2 and Case 3. Uniform translocations of the terminal part of the Yp-differential region to Xp-PAR1 have been reported previously (Jobling et al., 1998; Nakashima et al., 2014; Rouyer, Simmler, Page, \& Weissenbach, 1987; Sharp et al., 2005). The fork stalling, template switching, microhomology-mediated break-induced replication and nonhomologous end-joining (NHEJ) mechanisms could be the cause of such translocations and deletions (Giglio et al., 2002; Nakashima et al., 2014; Simmons, Carvalho, \& Lupski, 2012). There was no significant variation between these mechanisms with respect to the clinical findings of the patients. Also, the loss of very distal part of Xp-differential region in Cases 1, 5, 6, 7, 8 and duplication of the proximal PAR1 in Case 2 and Case 3 seem to have no significant effect on the clinical picture. 
The results of the $\mathrm{XCl}$ analysis of patients with 46,XX TDSD are controversial in the literature. Although some authors found skewed $\mathrm{XCl}$ patterns among these patients, the others could not confirm these results (Bouayed Abdelmoula et al., 2003; Gunes et al., 2013; Nakashima et al., 2014; Vorona et al., 2007). Dispate one of our patients had skewed $\mathrm{XCl}$ pattern, the remaining five patients had random $\mathrm{XCl}$ pattern in the present study. The patient with skewed $\mathrm{XCl}$ pattern had paracentric $\mathrm{Yp}$ inversion-mediated $X p ; Y p$ translocation. There were no significant differences between the patients with skewed $\mathrm{XCl}$ and the others based on clinical findings, especially regarding to the external genitalia. It has been proposed that $\mathrm{XCl}$ pattern is essential for the formation of external genitalia. Nakashima et al. (2014) reported that patients with random $\mathrm{XCl}$ had a normal male external genitalia; however, the patients with skewed $\mathrm{XCl}$ pattern that lead to inactivation of the expression of derivative $X$ chromosome-bearing $S R Y$ gene cause to hypogenitalismus including micropenis, microphallus, cryptorchidism and penoscrotal hypospadias. Our single patient with skewed XCI pattern had normal external male genitalia. However, we could not be able to identify whether the derivative $X$ chromosome was inactivated. Additionally, no correlation was found between the $\mathrm{XCl}$ status and the mechanism of translocation among our patients. These data are consistent with the findings of Nakashima and colleagues (Nakashima et al., 2014).

Case 8 demonstrated low level of X-chromosomal mosaicism, $46, X, \operatorname{der}(X) / 47, X, \operatorname{der}(X), \operatorname{der}(X) / 45, X$, and the clinical picture was not distinct from the diploid cases. $X$-chromosomal mosaicism in SRY-positive 46,XX TDSD has been reported in the literature previously, and mitotic nondisjunction has been suggested to be responsible for mosaicism (Chernykh et al., 2009; Macia Bobes, Alonso Troncoso, Botas Cervero, Castano Fernandez, \& Fau Cubero, 2002). Patients with mosaicism have a clinical variability ranging from the true hermaphrodites to complete masculinisation based on the proportion of cell lines (Chernykh et al., 2009). In our patient, the $46, X X$ cell line was predominant, and very low level of $45, X$ and $47, X, \operatorname{der}(X), \operatorname{der}(X)$ mosaicism was detected and having complete masculinisation is consistent with the previous studies.

\section{5 | CONCLUSION}

In brief, this study summarises the clinical and molecular data of a rare but important cause of male infertility. This report serves us to delineate the complex structure of the $X p ; Y p$ translocations caused by NAHR or replication-based mechanisms and the outcomes of the derived chromosome. Further studies on this clinically and genetically heterogeneous disorder could clarify the genomic basis of Xp;Yp translocations in 46,XX TDSD and their refined consequences. Finally, testicular sperm extraction is not recommended in these patients and adoption or in vitro fertilisation with a sperm donor should be considered.

\section{ACKNOWLEDGEMENT}

The authors thank all the staff of the andrology, medical biology and medical genetics laboratories for providing technical assistance in routine infertility test.

\section{CONFLICT OF INTEREST}

The authors declare no conflict of interests.

\section{ORCID}

Omer Salih Akar (iD https://orcid.org/0000-0001-5686-2185

Sezgin Gunes (D) https://orcid.org/0000-0002-3103-6482

Ummet Abur (iD https://orcid.org/0000-0002-4811-9321

Engin Altundag (iD https://orcid.org/0000-0001-8841-1426

Ramazan Asci iD https://orcid.org/0000-0002-2119-8963

Onur Emre Onat iD https://orcid.org/0000-0002-7105-1572

Tayfun Ozcelik (iD https://orcid.org/0000-0001-5937-1082

Gonul Ogur iD https://orcid.org/0000-0002-9944-4423

\section{REFERENCES}

Abur, U., Gunes, S., Ascı, R., Altundag, E., Akar, O. S., Ayas, B., ... Ogur, G. (2019). Chromosomal and $Y$ chromosome microdeletion analysis in 1,300 infertile males and the fertility outcome of patients with AZFc microdeletions. Andrologia, 51, e13402. https://doi.org/10.1111/ and.13402

Akinsal, E. C., Baydilli, N., Demirtas, A., Saatci, C., \& Ekmekcioglu, O. (2017). Ten cases with 46, XX testicular disorder of sex development: Single center experience. International Brazilian Journal of Urology, 43(4), 770-775. https://doi.org/10.1590/S1677-5538. IBJU.2016.0505

Anik, A., Catli, G., Abaci, A., \& Bober, E. (2013). 46, XX male disorder of sexual development:A case report. Journal of Clinical Research in Pediatric Endocrinology, 5(4), 258-260. https://doi.org/10.4274/ Jcrpe.1098

Aslan, Y., Atan, A., Omur Aydin, A., Nalcacioglu, V., Tuncel, A., \& Kadioglu, A. (2011). Penile length and somatometric parameters: A study in healthy young Turkish men. Asian Journal of Andrology, 13(2), 339341. https://doi.org/10.1038/aja.2010.109

Bouayed Abdelmoula, N., Portnoi, M.-F., Keskes, L., Recan, D., Bahloul, A., Boudawara, T., ... Rebai, T. (2003). Skewed X chromosome inactivation pattern in SRY positive XX maleness: A case report and review of literature. Annales de Genetique, 46(1), 11-18. https://doi. org/10.1016/S0003-3995(03)00011-X

Chen, T., Tian, L., Wu, F., Xuan, X., Ma, G., Tang, R., \& Lu, J. (2019). Clinical and genetic analysis in males with $46, \mathrm{XX}$ disorders of sex development: A reproductive centre experience of 144 cases. Andrologia, 51(4), e13232. https://doi.org/10.1111/and.13232

Chernykh, V. B., Kurilo, L. F., Shilova, N. V., Zolotukhina, T. V., Ryzhkova, O. P., Bliznetz, E. A., \& Polyakov, A. V. (2009). Hidden X chromosomal mosaicism in a 46,XX male. Sexual Development, 3(4), 183-187. https://doi.org/10.1159/000228718

Dauwerse, J. G., Hansson, K. B., Brouwers, A. A., Peters, D. J., \& Breuning, M. H. (2006). An XX male with the sex-determining region $Y$ gene inserted in the long arm of chromosome 16. Fertility and Sterility, 86(2), 463.e1-463.e5. https://doi.org/10.1016/j.fertnstert.2005.12.062

De la Chapelle, A., Hortling, H., Niemi, M., \& Wennström, J. (1964). XX Sex chromosomes in a human male. First case. Acta Medica Scandinavica, 175(Suppl 412), 25-38. https://doi.org/10.1111/j.0954-6820.1964. tb04630.x

Delot, E. C., Vilain, E. J.,(1993), Nonsyndromic 46, XX Testicular Disorders of Sex Development. In: Adam, M. P., Ardinger, H. H., 
Pagon, R. A., Wallace, S. E.,Bean, L. J. H., Stephens, K., \& Amemiya, A. (eds). GeneReviews((R)). Seattle (WA): University of Washington

Giglio, S., Calvari, V., Gregato, G., Gimelli, G., Camanini, S., Giorda, R., ... Zuffardi, O. (2002). Heterozygous submicroscopic inversions involving olfactory receptor-gene clusters mediate the recurrent $t(4 ; 8)$ (p16;p23) translocation. American Journal of Human Genetics, 71(2), 276-285. https://doi.org/10.1086/341610

Grinspon, R. P., \& Rey, R. A. (2019). Molecular Characterization of XX Maleness. Int J Mol Sci, 20(23), 6089.

Gunes, S., Asci, R., Okten, G., Atac, F., Onat, O. E., Ogur, G., ... Bagci, H. (2013). Two males with SRY-positive 46, XX testicular disorder of sex development. Systems Biology in Reproductive Medicine, 59(1), 42-47. https://doi.org/10.3109/19396368.2012.731624

Gunes, S., \& Esteves, S. C. (2020). Role of genetics and epigenetics in male infertility. Andrologia, e13586. https://doi.org/10.1111/and.13586

Jobling, M. A., Williams, G., Schiebel, K., Pandya, A., McElreavey, K., Salas, L., ... Tyler-Smith, C. (1998). A selective difference between human Y-chromosomal DNA haplotypes. Current Biology, 8(25), 1391-1394. https://doi.org/10.1016/s0960-9822(98)00020-7

Kamp, C., Huellen, K., Fernandes, S., Sousa, M., Schlegel, P. N., Mielnik, A., Kleiman, S., Yavetz, H., Krause, W., Kupker, W., Johannisson, R., Schulze, W., Weidner, W., Barros, A., \& Vogt, P. H. (2001). High deletion frequency of the complete AZFa sequence in men with Sertolicell-only syndrome. Mol Hum Reprod, 7, 987-994.

Kirsch, S., Weiss, B., Zumbach, K., \& Rappold, G. (2004). Molecular and evolutionary analysis of the growth-controlling region on the human Y chromosome. Human Genetics, 114(2), 173-181. https://doi. org/10.1007/s00439-003-1028-z

Krausz, C., \& Riera-Escamilla, A. (2018). Genetics of male infertility. Nat Rev Urol, 15, 369-384.

Macia Bobes, C., Alonso Troncoso, I., Botas Cervero, P., Castano Fernandez, G., \& Fau Cubero, C. (2002). Clinical and genetic study of a 46, XX man with occult mosaicism. Archivos Espanoles de Urologia, 55(8), 952-954.

Majzoub, A., Arafa, M., Starks, C., Elbardisi, H., Al Said, S., \& Sabanegh, E. (2017). 46 XX karyotype during male fertility evaluation; case series and literature review. Asian Journal of Andrology, 19(2), 168-172. https://doi.org/10.4103/1008-682X.181224

Nakashima, S., Ohishi, A., Takada, F., Kawamura, H., Igarashi, M., Fukami, M., \& Ogata, T. (2014). Clinical and molecular studies in four patients with SRY-positive 46, XX testicular disorders of sex development: Implications for variable sex development and genomic rearrangements. Journal of Human Genetics, 59(10), 549-553. https://doi. org/10.1038/jhg.2014.70

Ozer, B. (2008). Secular trend in body height and weight of Turkish adults. Anthropological Science, 116(3), 191-199. https://doi.org/10.1537/ ase.061213

Pinkel, D., Segraves, R., Sudar, D., Clark, S., Poole, I., Kowbel, D., ... Albertson, D. G. (1998). High resolution analysis of DNA copy number variation using comparative genomic hybridization to microarrays. Nature Genetics, 20(2), 207-211. https://doi.org/10.1038/2524

Queralt, R., Madrigal, I., Vallecillos, M. A., Morales, C., Ballescá, J.-L., Oliva, R., ... Margarit, E. (2008). Atypical XX male with the SRY gene located at the long arm of chromosome 1 and a 1qter microdeletion. American Journal of Medical Genetics. Part A, 146A(10), 1335-1340. https://doi.org/10.1002/ajmg.a.32284

Rappold, G. A., Fukami, M., Niesler, B., Schiller, S., Zumkeller, W., Bettendorf, M., ... Ogata, T. (2002). Deletions of the homeobox gene SHOX (short stature homeobox) are an important cause of growth failure in children with short stature. Journal of Clinical Endocrinology and Metabolism, 87(3), 1402-1406. https://doi.org/10.1210/ jcem.87.3.8328

Rhoden, E. L., \& Morgentaler, A. (2004). Treatment of testosterone-induced gynecomastia with the aromatase inhibitor, anastrozole. International Journal of Impotence Research, 16(1), 95-97. https://doi. org/10.1038/sj.ijir.3901154

Rooney, D. E. (2001). Human cytogenetics: A practical approach (3rd ed.). Oxford, UK and New York, NY: Oxford University Press.

Ropke, A., \& Tuttelmann, F. (2017). Mechanisms in endocrinology: Aberrations of the $X$ chromosome as cause of male infertility. European Journal of Endocrinology, 177(5), R249-R259. https://doi. org/10.1530/EJE-17-0246

Rouyer, F., Simmler, M. C., Page, D. C., \& Weissenbach, J. (1987). A sex chromosome rearrangement in a human XX male caused by Alu-Alu recombination. Cell, 51(3), 417-425. https://doi.org/10.1016/00928674(87)90637-4

Sharp, A., Kusz, K., Jaruzelska, J., Tapper, W., Szarras-Czapnik, M., Wolski, J., \& Jacobs, P. (2005). Variability of sexual phenotype in 46 , $\mathrm{XX}(\mathrm{SRY}+)$ patients: The influence of spreading $\mathrm{X}$ inactivation versus position effects. Journal of Medical Genetics, 42(5), 420-427. https:// doi.org/10.1136/jmg.2004.022053

Simmons, A. D., Carvalho, C. M., \& Lupski, J. R. (2012). What have studies of genomic disorders taught us about our genome? Methods in Molecular Biology, 838, 1-27. https://doi.org/10.1007/978-1-61779 -507-7_1

Soylemez, H., Atar, M., Sancaktutar, A. A., Penbegul, N., Bozkurt, Y., \& Onem, K. (2012). Relationship between penile size and somatometric parameters in 2276 healthy young men. International Journal of Impotence Research, 24(3), 126-129. https://doi.org/10.1038/ ijir.2011.53

Swerdloff, R. S., \& Ng, C. M. (2000). Gynecomastia: Etiology, diagnosis, and treatment. In K. R. Feingold, B. Anawalt, A. Boyce, G. Chrousos, K. Dungan, A. Grossman, ... D. P. Wilson (Eds.), Endotext. South Dartmouth, MA: MDText.com, Inc.

Velasco, G., Savarese, V., Sandorfi, N., Jimenez, S. A., \& Jabbour, S. (2011). 46, XX SRY-positive male syndrome presenting with primary hypogonadism in the setting of scleroderma. Endocrine Practice, 17(1), 95-98. https://doi.org/10.4158/EP10184.CR

Vorona, E., Zitzmann, M., Gromoll, J., Schuring, A. N., \& Nieschlag, E. (2007). Clinical, endocrinological, and epigenetic features of the 46 , XX male syndrome, compared with $47, \mathrm{XXY}$ Klinefelter patients. Journal of Clinical Endocrinology and Metabolism, 92(9), 3458-3465. https://doi.org/10.1210/jc.2007-0447

Wang, I., Weil, D., Levilliers, J., Affara, N. A., de la Chapelle, A., \& Petit, C. (1995). Prevalence and molecular analysis of two hot spots for ectopic recombination leading to XX maleness. Genomics, 28(1), 52-58. https://doi.org/10.1006/geno.1995.1105

Zenteno-Ruiz, J. C., Kofman-Alfaro, S., \& Mendez, J. P. (2001). 46, XX sex reversal. Archives of Medical Research, 32(6), 559-566. https://doi. org/10.1016/S0188-4409(01)00322-8

How to cite this article: Akar ÖS, Gunes S, Abur Ü, et al. Multiscale analysis of SRY-positive 46,XX testicular disorder of sex development: Presentation of nine cases. Andrologia. 2020;52:e13739. https://doi.org/10.1111/and.13739 